\title{
Complexo hidrossolúvel na formação de mudas do porta-enxerto limoeiro 'Cravo'
}

\author{
Water-soluble complex in the formation of rootstock seedlings of Rangpur \\ Mauro Brasil Dias Tofanelli, Rodrigo Teles dos Santos \& Jair Fernando Kogeratski \\ Universidade Federal do Paraná, Curitiba, PR, Brasil. *Autor para correspondência: mbrasildt@ufpr.br.
}

Submissão: 13/04/2017 | Aceite: 13/06/2018

\begin{abstract}
RESUMO
A formação de mudas frutíferas é uma fase importante da cadeia produtiva da fruticultura e na citricultura não é diferente, sobretudo na produção de mudas de qualidade. O uso de fontes alternativas de nutrientes minerais ofereceria novas opções de produto para fertilização aplicadas à agricultura moderna. Este trabalho teve como objetivo avaliar o crescimento e desenvolvimento de mudas de limoeiro 'Cravo' submetidas à aplicação de complexo hidrossolúvel em diferentes concentrações como fonte alternativa de nutrientes minerais. O experimento foi conduzido entre os meses de novembro de 2012 a abril de 2013, cujas mudas foram formadas em tubetes durante 150 dias. O complexo hidrossolúvel $(\mathrm{CH})$ foi aplicado em cobertura mediante irrigação mensal com soluções nas concentrações de $0,1,2,4$ e $8 \mathrm{~g} \mathrm{~L}^{-1}$ sobre as mudas com ou sem adubação química convencional. As características avaliadas foram altura, diâmetro do colo, número de folhas, comprimento de raiz, massas fresca e seca da parte aérea e do sistema radicular, comprimento total de raízes e volume radicular. $\mathrm{O} \mathrm{CH}$ influenciou na altura e diâmetro das mudas de limoeiro 'Cravo', cujas estimativas concentrações entre 4 e $8 \mathrm{~g} \mathrm{~L}^{-1}$ tenderam a promover melhores resultados. A adubação de cobertura com o $\mathrm{CH}$ associado à adubação química convencional promoveu melhor formação radicular em comprimento e volume, exceto quando se aplicou de $8 \mathrm{~g} \mathrm{~L}^{-1}$ do $\mathrm{CH}$.
\end{abstract}

PALAVRAS-CHAVE: Citrus limonia Osbeck, propagação, adubação de cobertura, crescimento.

\begin{abstract}
Seedling fruit formation is an important stage of fruit production, this also being true for citrus cultivation, especially for producing quality seedlings. The use of alternative sources of mineral nutrients could offer novel fertilizer options for modern agriculture. The objective of this study was to evaluate the growth and development of Rangpur seedlings subjected to water-soluble complex application at different concentrations as an alternative source of mineral nutrients. The experiment was developed from November 2012 to April 2013, and the Rangpur seedlings were stored in plastic tubes during 150 days. The water-soluble complex (WSC) was applied as dressing through monthly irrigation with solutions at concentrations of $0,1,2,4$ and $8 \mathrm{~g} \mathrm{~L}^{-1}$ on seedlings with or without conventional chemistry fertilization. The characteristics evaluated were seedling height, stem base diameter, number of leaves, root length, fresh and dry mass of the aerial part as well as of the root system, total root length, and root volume. The WSC influenced the height and diameter of Rungpur seedlings, whose estimated concentrations between 4 and $8 \mathrm{~g} \mathrm{~L}^{-1}$ tended to have better results. The dressing with WSC, when compared to conventional chemistry fertilization showed better root formation both in length and volume, except when $8 \mathrm{~g} \mathrm{~L}^{-1}$ was applied.
\end{abstract}

KEYWORDS: Citrus limonia Osbeck, propagation, dressing, growth.

\section{INTRODUÇÃO}

$\mathrm{Na}$ agricultura moderna, manter ou melhorar a qualidade e/ou quantidade da produção vegetal e ao mesmo tempo diminuir custo e adotar medidas ecologicamente corretas parece ser o grande desafio dos sistemas produtivos da atualidade, sobretudo, diante da falta de tecnologias apropriadas e de princípios norteadores (TOFANELLI \& SILVA 2011). Atualmente, há uma tendência na agricultura mundial de se buscar novas práticas, técnicas e/ou produtos que sejam tanto quanto eficientes aos tradicionais ou químicos (sintéticos), mas que, concomitantemente, sejam menos ou não sejam degradantes, poluentes e onerosos. 
O Brasil é referência mundial na produção de cítricos, sendo o segundo maior produtor com 19,6 milhões toneladas de citros colhidas em 2016 (FAO 2018) e destas apenas o estado de São Paulo é responsável pela produção de 14,1 milhões de toneladas de laranjas, limões e tangerinas (IBGE 2018). Apesar do panorama do agronegócio citricultura no Brasil ser altamente favorável ao país no contexto mundial, a manutenção deste destaque sempre dependerá da tecnologia de manejo em toda a sua cadeia produtiva. Neste sentido é que se deve dar atenção especial à fase de produção de mudas, partindo do princípio de que a muda de qualidade é um dos alicerces da fruticultura e de que tal posição de destaque da citricultura só será mantida com a utilização de mudas de alta qualidade na formação e renovação dos pomares cítricos (FRANZÃO et al. 2009, PRADO et al. 2009, ROZANE et al. 2009). Para KOLLER (2006) a muda cítrica é o insumo mais importante na formação de um pomar, sendo a sua qualidade dependente da garantia genética, dos métodos de propagação, sistemas de produção e legislação vigente.

Os pomares cítricos comerciais no Brasil são predominantemente formados por plantas enxertadas cujas cultivares-copa foram enxertadas sobre porta-enxertos propagados por sementes (KOLLER 2006, KOLLER 2009, PRADO et al. 2009). Dentre os porta-enxertos mais utilizados na citricultura brasileira cita-se o limoeiro ou tangerineira 'Cravo' (Citrus limonia Osbeck) (FRANZÃO et al. 2009, ROZANE et al. 2009, WEILER et al. 2009, CUNHA SOBRINHO et al. 2013).

A fertilização e a nutrição de mudas desempenham relação direta com a sua qualidade e é, principalmente, no substrato onde os nutrientes minerais necessários para o crescimento e desenvolvimento das mudas estão presentes (HARTMANN et al. 2010, SILVA et al. 2010). Porém, mesmo que o substrato contenha excelentes propriedades químicas, as plantas (mudas) nem sempre desempenham aproveitamento máximo dos nutrientes minerais nele presentes por influência da interação entre vários fatores endógenos e exógenos como a temperatura, umidade, radiação, oxigênio, estados nutricional, energético e hormonal, as constituições líquida e estrutural das células, anatomia e morfologia dos órgãos vegetais, idade do vegetal, presença de organismos simbióticos no solo ou substrato, condição fitossanitária, dentre outros (RAVEN et al. 2001, KIRKBY \& RÖMHELD 2007, FREITAS et al. 2009, TAIZ \& ZEIGER 2009, TOFANELLI \& SILVA 2011).

A fertilização ou adubação, que consiste no uso de fontes de nutrientes minerais administrados via solo ou foliar, é empregada para promover melhor nutrição das mudas em viveiros e, consequentemente, seu maior crescimento e desenvolvimento. Normalmente, as fontes minerais sintéticas são mais utilizadas, porém são onerosas e ecologicamente questionáveis (INOCÊNCIO et al. 2009, SÁ et al. 2010, BERNARDI et al. 2012). Trabalhos têm sido realizados para avaliar o uso de produtos ou compostos alternativos como fertilizantes associados ou não às fontes sintéticas na formação de mudas de porta-enxertos cítricos (CARNEIRO et al. 2011, MACHADO et al. 2011).

Para TOFANELLI et al. (2016) há uma tendência mundial de substituição destes fertilizantes químicos por adubos cuja fonte não seja sintética e por isso têm surgido produtos alternativos no mercado para uso na agricultura que ofereçam maior segurança alimentar, ambiental e social.

Calcários, fosfatos naturais, rochas moídas, farinhas, vinhotos, xistos, esgotos e outros são algumas alternativas de fornecimento de macronutrientes e micronutrientes às plantas em detrimento aos fertilizantes sintéticos (TOFANELLI \& SILVA 2011, ALMEIDA et al. 2012).

O presente trabalho teve como objetivo avaliar o efeito da aplicação de diferentes concentrações do complexo hidrossolúvel como fonte de nutrientes minerais no crescimento e desenvolvimento de mudas do porta-enxerto limoeiro 'Cravo'.

\section{MATERIAL E MÉTODOS}

Em novembro de 2012, sementes do limoeiro 'Cravo' foram extraídas de frutos selecionados de plantas de dez anos de idade e polvilhadas logo em seguida com pó de cal para retirar a mucilagem e facilitar a limpeza, procedendo-se em seguida a lavagem das sementes em peneira para retirada da pasta de cal formada e, por fim, colocadas para secar à sombra por 48 horas. A semeadura foi realizada em tubetes de $240 \mathrm{~cm}^{3}$ de volume, $5,3 \mathrm{~cm}$ de diâmetro e $19 \mathrm{~cm}$ de comprimento contendo substrato a base de terra-de-barranco + areia lavada + esterco bovino $(4: 1: 1 \mathrm{v} / \mathrm{v})+1 \mathrm{~kg}$ de calcário dolomítico por $\mathrm{m}^{3}$ da mistura, colocando-se 2 sementes por tubete à profundidade de $1 \mathrm{~cm}$. Os tubetes então foram colocados em bandejas plásticas com 54 células e acondicionados em estufa tipo capela com cobertura de filme plástico de polietileno de baixa densidade e 150 mícrons de espessura.

Após a emergência e estabilização dos "seedlings", que ocorreu quando a maioria das mudinhas atingiu $10 \mathrm{~cm}$ de altura, foi realizado desbaste preservando-se o melhor indivíduo. As mudas foram mantidas na estufa plástica onde receberam irrigação manual diária com auxílio de um regador. 
Foi retirada uma amostra do substrato antes de receber o calcário para análise de suas propriedades químicas e físicas, cujos resultados foram: $\mathrm{pH}\left(\mathrm{CaCl}_{2}\right): 6,3 ; \mathrm{P}: 232,0 \mathrm{mg} \mathrm{dm}^{-3} ; \mathrm{K}^{+}: 1,68 \mathrm{cmol}_{\mathrm{c}} \mathrm{dm}^{-3} ; \mathrm{Ca}^{+2}$ : $11,19 \mathrm{cmol}_{\mathrm{c}} \mathrm{dm}^{-3} ; \mathrm{Mg}^{+2}: 3,41 \mathrm{cmol}_{\mathrm{c} \mathrm{dm}}{ }^{-3} ; \mathrm{Al}^{+3}: 0,0 \mathrm{cmol}_{\mathrm{c}} \mathrm{dm}^{-3} ; \mathrm{H}^{+}+\mathrm{Al}^{+3}: 3,0 \mathrm{cmol}_{\mathrm{c}} \mathrm{dm}^{-3}$; soma de bases (SB): $16,28 \mathrm{cmol}_{\mathrm{c}} \mathrm{dm}^{-3}$; CTC a pH 7,0 (T): 19,28 $\mathrm{cmol}_{\mathrm{c}} \mathrm{dm}^{-3}$; C: $36,3 \mathrm{~g} \mathrm{dm}^{-3}$ e saturação de base (V): $84 \%$.

Os tratamentos experimentais foram constituídos pela aplicação do complexo hidrossolúvel $(\mathrm{CH})$ nas concentrações $0,1,2,4$ e $8 \mathrm{~g} \mathrm{~L}^{-1}$ e pela presença ou ausência de adubação química, definindo um esquema fatorial $4 \times 2$. O delineamento experimental foi inteiramente casualizado com três repetições dispostas nas bandejas em parcelas contendo 16 mudas cada uma distribuídas de maneira que se formasse um quadrado (4 mudas $\times 4$ mudas), sendo consideradas úteis as quatro centrais.

$\mathrm{O} \mathrm{CH}$ foi fornecido pela fabricante Müller Stecz Indústria (Piraquara, PR) comercializado sob a marca Systema Clorofila ${ }^{\circledR}$ em pastilhas de 5 gramas e conforme especificações do fabricante tal produto trata-se de um complexo hidrossolúvel cuja composição provém de reações básicas formadoras de quelatos de ácido cítrico, carbonatos e bicarbonatos de metais, com o Fosfato de Araxá adicionado como lubrificante e o Calcário de Xisto como espessante (Calcário de Xisto Tensoativo + Fosfato Natural Ativado). A composição marcada $(\mathrm{p} / \mathrm{v})$ do complexo é $\mathrm{Mg}$ - magnésio (12\%), $\mathrm{N}$ - nitrogênio $(9,5 \%), \mathrm{K}$ - potássio $(9 \%), \mathrm{Na}$ - sódio (9\%), Ca - cálcio (5\%), S - enxofre (4,5\%), P - fósforo (3,5\%), Mn - manganês (1\%), Fe - ferro (1\%), Cu cobre (1\%), B - boro (0,5\%), Ni - níquel $(0,5 \%)$, Se - selênio $(0,05 \%)$, Li - lítio $(0,02 \%), \mathrm{Zn}$ - zinco $(0,02 \%)$, Co - cobalto $(0,01 \%)$ e Mo - molibdênio $(0,01 \%)$. O produto então é resultado da reunião por síntese dos reagentes com componentes naturais como o Calcário de Xisto e o Fosfato de Araxá.

Para a aplicação do $\mathrm{CH}$ foram preparadas soluções diluindo-se o produto em água destilada conforme suas respectivas concentrações e, posteriormente, aplicadas sobre as mudas mediante irrigação mensal com uso de regador, sendo a primeira aplicação realizada logo após a semeadura. $O$ volume de aplicação de todas as soluções foi na base de $40 \mathrm{~mL}^{\text {muda }}{ }^{-1}$. Já o tratamento adubação química convencional (AQC) foi realizado mediante adubação de base adicionando-se no substrato $5,0 \mathrm{~kg}$ de Superfosfato Simples $\left(20 \%\right.$ de $\left.\mathrm{P}_{2} \mathrm{O}_{5}\right)$ e $0,5 \mathrm{~kg}$ de Cloreto de Potássio $(60 \% \mathrm{KCl})$ por $\mathrm{m}^{3}$ e adubações de cobertura com aplicações mensais de $\mathrm{N}$ mediante irrigação com solução de Uréia a $1 \%$ até a coleta dos dados, sendo a primeira adubação nitrogenada realizada logo após a operação de desbaste.

Aos 150 dias após a semeadura foram coletados os dados das mudas do limoeiro 'Cravo' avaliandose a altura da muda, o diâmetro do colo, número de folhas por muda, comprimento da maior raiz, massas frescas e seca da parte aérea e das raízes e comprimento total de raízes, sendo este último obtido com auxílio do equipamento WinRhizo. As mudas foram retiradas dos tubetes, destorroadas e o seu sistema radicular lavado em água corrente sobre peneira de $2 \mathrm{~mm}$ de malha. Para a determinação da altura da muda utilizou-se uma régua graduada em milímetro, medindo a distância entre o colo e o ápice da muda. $\mathrm{O}$ diâmetro do colo foi medido a $1 \mathrm{~cm}$ acima da superfície do substrato com auxílio de um paquímetro analógico com a leitura dada em milímetro. Para a medição do comprimento da maior raiz, utilizou-se uma régua graduada em milímetro. A massa fresca tanto da parte aérea quanto das raízes foi determinada separando-se estas duas porções mediante corte na região do colo para posterior pesagem em balança de precisão. Já a massa seca foi determinada colocando-se os respectivos materiais dentro de sacos de papel individuais em estufa a $60 \stackrel{\circ}{\circ}$ até que se estabilizasse o peso de cada amostra para então efetuar a sua pesagem na balança de precisão. Para determinar comprimento total de raízes cada respectiva matéria foi disposta sobre uma placa de acrílico tamanho A4 $(210 \times 297 \mathrm{~mm}) \mathrm{com}$ borda de $1 \mathrm{~cm}$ de altura preenchido com água potável, e foram digitalizadas em um Scanner LA1600 acoplado ao programa computacional WinRhizo.

As análises estatísticas foram realizadas mediante análise de variância dos dados observados, realizando-se a comparação de médias pelo teste de Tukey a $5 \%$ de significância para os fatores de variação. Quando necessário, foi realizada regressão polinomial para avaliar o efeito das concentrações do produto mediante estimativas obtidas pelas equações, considerando significativos os ajustes com probabilidade $<0,05$ e coeficiente de determinação $\left(R^{2}\right) \geq 0,75$. As análises foram processadas no software estatístico Sisvar 5.3 (FERREIRA 2010).

\section{RESULTADOS E DISCUSSÃO}

Houve interação significativa entre a aplicação do complexo hidrossolúvel $(\mathrm{CH})$ e a adubação química convencional $(A Q C)$ nas características comprimento da maior raiz e volume radicular (Tabela 1). A aplicação de $4 \mathrm{~g} \mathrm{~L}^{-1}$ do $\mathrm{CH}$ em mudas de limoeiro 'Cravo' associada à AQC promoveu melhor resultado de crescimento da maior raiz $(20,26 \mathrm{~cm})$, embora não tenha sido estatisticamente superior ao tratamento que recebeu apenas $A Q C$ e aos tratamentos com 2 e $4 \mathrm{~g} \mathrm{~L}^{-1}$ do $\mathrm{CH}$ independentemente da ausência ou 
presença da AQC. Neste caso, a concentração de $8 \mathrm{~g} \mathrm{~L}^{-1}$ do $\mathrm{CH}$ associada à AQC pode ter fornecido nutrientes em excesso promovendo efeito negativo em virtude da alta dosagem.

Tabela 1. Comprimento de raiz (CR) e volume de raízes (VR) de mudas de limoeiro 'Cravo' submetidas à fertilização com diferentes concentrações do complexo hidrossolúvel $(\mathrm{CH})$ associado ou não à adubação química convencional (AQC).

Table 1. Root length (RL) and root volume (RV) of Rangpur seedlings fertilized with water-soluble complex (WSC) at different concentrations with or without conventional chemistry fertilization (CCF).

\begin{tabular}{lllll}
\hline $\mathrm{CH}\left(\mathrm{g} \mathrm{L}^{-1}\right)$ & \multicolumn{2}{c}{$\mathrm{CR}(\mathrm{cm})$} & \multicolumn{2}{c}{ VR $\left(\mathrm{cm}^{3}\right)$} \\
\cline { 2 - 5 } & $\mathrm{sem}$ & $\mathrm{com}$ & sem & com \\
\hline 0 & $17,87 \mathrm{aB}{ }^{(1)}$ & $20,04 \mathrm{aA}$ & $0,51 \mathrm{aB}$ & $1,94 \mathrm{bA}$ \\
1 & $19,10 \mathrm{aA}$ & $19,66 \mathrm{abA}$ & $0,95 \mathrm{aB}$ & $2,80 \mathrm{abA}$ \\
2 & $18,71 \mathrm{aA}$ & $19,25 \mathrm{abA}$ & $0,79 \mathrm{aB}$ & $3,90 \mathrm{aA}$ \\
4 & $17,61 \mathrm{aB}$ & $20,26 \mathrm{aA}$ & $0,82 \mathrm{aB}$ & $2,80 \mathrm{abA}$ \\
8 & $19,60 \mathrm{aA}$ & $17,91 \mathrm{bB}$ & $0,99 \mathrm{aB}$ & $2,29 \mathrm{bA}$ \\
\hline $\mathrm{CV}(\%)$ & 11,4 & & 25,9 & \\
\hline
\end{tabular}

Médias seguidas por letras distintas, minúscula na coluna e maiúscula na linha, em cada característica diferem entre si ao nível de 5\% de probabilidade. $\mathrm{CV}$ = Coeficiente de variação.

Já para o volume de raízes, a aplicação do $\mathrm{CH}$ quando se utilizou a $\mathrm{AQC}$ foi importante para melhorar a formação de raízes, ao passo que na ausência do adubo químico $\circ \mathrm{CH}$ não influenciou nesta característica e foi sempre menor quando comparado aos tratamentos referentes à associação da AQC + $\mathrm{CH}$, independente da concentração deste (Tabela 1). A adubação de cobertura com $2 \mathrm{~g} \mathrm{~L}^{-1}$ do $\mathrm{CH}$ nas mudas de limoeiro 'Cravo' que receberam a AQC promoveu maior volume radicular $\left(3,90 \mathrm{~cm}^{3}\right)$, embora tenha sido estatisticamente equivalente aos tratamentos com 1 e $4 \mathrm{~g} \mathrm{~L}^{-1}$.

A qualidade do sistema radicular, especialmente a profundidade e a quantidade das raízes têm sido consideradas características importantes na formação de uma boa muda, pois durante o estabelecimento à campo as mudas com raízes mais profundas e volumosas seriam mais eficientes na busca pela água e sobreviveriam melhor em períodos mais longos de estiagem (BERNARDI et al. 2000ab, THOMAZ et al. 2011).

Apesar de ser conhecido o fato de que os surtos de crescimento da parte aérea e do sistema radicular ocorrem em momentos distintos e alternados (BERNARDI et al. 2000ab, RAMOS et al. 2010, CARNEIRO et al. 2011), para JABUR \& MARTINS (2002) o desenvolvimento da parte aérea em altura é determinado pelo comprimento do sistema radicular, corroborando com TEIXEIRA et al. (2009) que estudaram o desenvolvimento vegetativo de porta-enxertos de citros em diferentes recipientes e afirmaram que um maior crescimento do sistema radicular culmina, por conseguinte, num maior crescimento da parte aérea em mudas.

A altura, diâmetro do colo e o volume de raízes das mudas de limoeiro 'Cravo' obtiveram regressão polinomial significativa para o efeito das concentrações do FA. Houve tendência de aumento na altura das mudas até a concentração de $4,81 \mathrm{~g} \mathrm{~L}^{-1}$ do $\mathrm{CH}$ onde foi estimada uma altura máxima de $15,1 \mathrm{~cm}$ (Figura 1).

Já para diâmetro do colo, houve aumento desta característica até a concentração de $5,44 \mathrm{~g} \mathrm{~L}^{-1}$ do $\mathrm{FA}$, onde o diâmetro do colo máximo estimado foi de 2,76 mm (Figura 2).

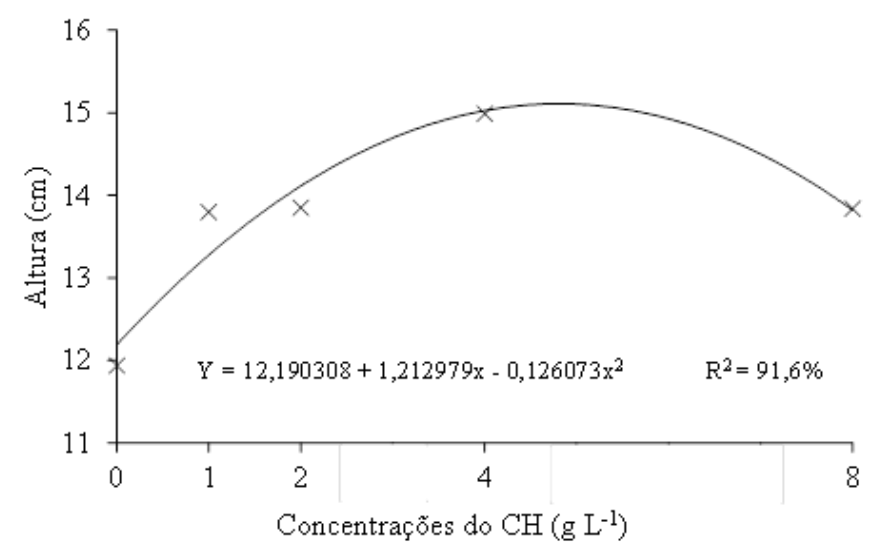

Figura 1. Altura de mudas de limoeiro 'Cravo' submetidas ao tratamento com o complexo hidrossolúvel (CH). Figure 1. Height of Rangpur seedlings fertilized with water-soluble complex (WSC). 


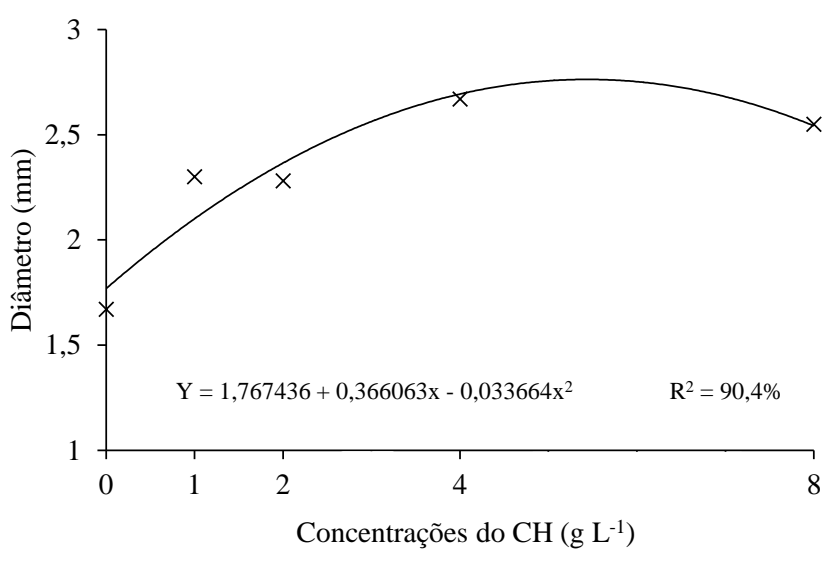

Figura 2. Diâmetro do colo de mudas de limoeiro 'Cravo' submetidas ao tratamento com o complexo hidrossolúvel $(\mathrm{CH})$.

Figure 2. Stem base diameter of Rangpur seedlings fertilized with water-soluble complex (WSC).

Para a característica volume radicular as regressões obtiveram baixos valores de coeficiente de determinação, não sendo neste caso interessante representar graficamente o efeito estimado das concentrações do $\mathrm{CH}$ para esta característica.

Diversos trabalhos ressaltam a relação que existe entre o aumento do diâmetro do caule de mudas cítricas com o incremento dos demais componentes do crescimento vegetativo, neste caso a altura estaria em destaque. Neste contexto, BERNARDI et al. (2008) observaram crescimento máximo em altura (13,2 $\mathrm{cm})$ e diâmetro $(4,4 \mathrm{~mm})$ de mudas de limoeiro 'Cravo' cultivadas em substrato com zeólita enriquecida com NPK quando estimaram as respectivas dosagens de 5,7 e 6,7 g por planta da adubação e consideraram que o diâmetro do caule tem relação direta com a altura das plantas. Já SCIVITTARO et al. (2004), estudando a adubação nitrogenada na formação de porta-enxertos do limoeiro 'Cravo', observaram que o $\mathrm{N}$ aplicado apenas influenciou na altura e no diâmetro do caule das mudas e que os respectivos valores máximos estimados de $13,6 \mathrm{~cm}$ e $2,1 \mathrm{~mm}$ foram obtidos pelas dosagens próximas de 0,37 e $0,36 \mathrm{~g} \mathrm{~L}^{-1} \mathrm{de} \mathrm{N}^{\mathrm{N}}$, respectivamente. Em outro sentido, SCHÄFER et al. (2006) avaliando o desenvolvimento vegetativo inicial de porta-enxertos cítricos cultivados em diferentes substratos, destacaram os piores resultados dos componentes do crescimento vegetativo aos quais foram obtidos por um mesmo substrato.

Em contrapartida, nem sempre o crescimento em altura de mudas pode ser relacionado com outras características do crescimento vegetal, inclusive com o diâmetro do caule, como observaram PRADO et al. (2009) e CARNEIRO et al. (2011) em estudos desenvolvidos para avaliar a formação de mudas cítricas submetidas à sistemas de fertilização.

Já ROZANE et al. (2009), VALE \& PRADO (2009) e ALMEIDA et al. (2012) destacaram a relação existente entre o fornecimento crescente de $P$ às mudas de porta-enxertos de citros e o aumento do diâmetro das mesmas. Neste contexto, provavelmente, o $\mathrm{P}$ presente no $\mathrm{CH}$ a 3,5\% pode ter sido importante para o incremento em espessura do caule das mudas de limoeiro 'Cravo'.

Porém, a partir de certo ponto no fornecimento de doses crescentes de nutrientes pode haver queda no crescimento e desenvolvimento dos vegetais muito provavelmente por conta do excesso nos teores dos elementos minerais presentes no substrato. Neste tocante, observou-se no presente trabalho que a partir de determinada concentração do $\mathrm{CH}$ houve diminuição nos valores de altura e diâmetro do colo das mudas (Figuras 1 e 2), possivelmente, porque houve a partir daí efeito negativo ao crescimento vegetal em resultado ao excesso nos teores de nutrientes minerais fornecidos.

ROZANE et al. (2009) e VALE \& PRADO (2009) também observaram diminuição no crescimento e desenvolvimento de mudas de limoeiro 'Cravo' a partir de um certo ponto no fornecimento de dosagens crescentes de NPK. Porém, CARNEIRO et al. (2011) observaram aumento linear no crescimento em altura de mudas do limoeiro 'Cravo' até a concentração de $2 \mathrm{~mL} \mathrm{~L}^{-1}$ do adubo organomineral $(11 \%$ de nitrogênio total, $6 \%$ de óxido de potássio e $1 \%$ carbono orgânico) aplicado sobre as mudas e atribuíram a isso ao aumento das doses de nutrientes fornecidas pelas maiores dosagens que foram necessárias para suprir a demanda dos nutrientes durante a fase vegetativa, destacando neste caso o $\mathrm{N}$. Dentre os vários elementos minerais componentes do $\mathrm{CH}$ utilizado no presente trabalho, o $\mathrm{N}$ está presente no mesmo na proporção de 9,5\%, o que pode ter influenciado positivamente no crescimento em altura das mudas de limoeiro 'Cravo'.

Para as características número de folhas, massas fresca e seca da parte aérea, massas fresca e seca de raízes e comprimento total de raízes somente houve efeito da AQC (Tabela 2). 
Tabela 2. Número de folhas (NF), massa fresca da parte aérea (MFA), massa seca da parte aérea (MSA), massa fresca das raízes (MFR), massa seca das raízes (MSR), comprimento total de raízes (CTR) de mudas de limoeiro 'Cravo' submetidas à adubação química convencional (AQC).

Table 2. Number of leaves (NL), fresh mass of the aerial part (FMAP), dry mass of the aerial part (DMAP), fresh mass of the root system (FMRS), dry mass of the root system (DMRS), and total root length (TRL) of Rangpur seedlings fertilized with conventional chemical fertilization (CCF).

\begin{tabular}{lllllll}
\hline AQC & NF & $\begin{array}{l}\text { MFA } \\
(\mathrm{g})\end{array}$ & $\begin{array}{l}\text { MSA } \\
(\mathrm{g})\end{array}$ & $\begin{array}{l}\text { MFR } \\
(\mathrm{g})\end{array}$ & $\begin{array}{l}\text { MSR } \\
(\mathrm{g})\end{array}$ & $\begin{array}{l}\text { CTR } \\
(\mathrm{cm})\end{array}$ \\
\hline Sem & $6,48 \mathrm{~b}^{(1)}$ & $0,84 \mathrm{~b}$ & $0,28 \mathrm{~b}$ & $0,75 \mathrm{~b}$ & $0,21 \mathrm{~b}$ & $194,38 \mathrm{~b}$ \\
Com & $13,55 \mathrm{a}$ & $3,17 \mathrm{a}$ & $1,06 \mathrm{a}$ & $2,77 \mathrm{a}$ & $0,79 \mathrm{a}$ & $495,50 \mathrm{a}$ \\
\hline CV $(\%)$ & 15,4 & 21,6 & 26,3 & 26,8 & 32,8 & 23,3 \\
\hline
\end{tabular}

Médias seguidas por letras distintas na coluna em cada característica diferem entre si ao nível de $5 \%$ de probabilidade. CV = Coeficiente de variação.

Vários trabalhos comprovaram os efeitos positivos do fornecimento de nutrientes às mudas cítricas via fontes químicas, principalmente, quanto aos elementos minerais $\mathrm{N}, \mathrm{P}$ e $\mathrm{K}$, pois tais elementos têm grande importância metabólica e, consequentemente, fisiológica e morfológica nos vegetais já que o $\mathrm{N}$ é constituinte de todas as proteínas e de muitos componentes da célula vegetal, atuando diretamente sobre 0 crescimento e o metabolismo vegetal, interfere diretamente no balanço entre o sistema radicular e a parte aérea e sob baixa disponibilidade de $\mathrm{N}$ ocorrem alterações morfológicas no vegetal, por sua vez o $\mathrm{P}$ é responsável pela transferência de energia aos processos metabólicos das plantas e o K está envolvido no equilíbrio osmótico e iônico e na regulação estomática, é ativador de muitas enzimas e quando fornecido às plantas tem promovido relações positivas entre crescimento das folhas e fotossíntese (BERNARDI et al. 2000ab, RAVEN et al. 2001, SCIVITTARO et al. 2004, ROZANE et al. 2009, TAIZ \& ZEIGER 2009, VALE et al. 2009, VALE \& PRADO 2009, TOFANELLI \& SILVA 2011, ALMEIDA et al. 2012).

\section{CONCLUSÃO}

O complexo hidrossolúvel $(\mathrm{CH})$ melhora a qualidade das mudas de limoeiro 'Cravo', especialmente, quanto à sua altura e ao seu diâmetro do colo.

Mudas do limoeiro 'Cravo' tratadas com $4 \mathrm{~g} \mathrm{~L}^{-1}$ do $\mathrm{CH}$ em associação com a adubação química convencional apresentam melhor aprofundamento da raiz principal e maior formação radicular em volume.

As concentrações de 4 e $8 \mathrm{~g} \mathrm{~L}^{-1}$ de $\mathrm{CH}$ aplicadas em mudas de limoeiro 'Cravo' promovem melhores resultados na sua formação em altura e diâmetro de colo.

O CH não deve ser a única fonte de adubação para a formação de mudas de limoeiro 'Cravo'.

\section{REFERÊNCIAS}

ALMEIDA JPN et al. 2012. Utilização de esgoto doméstico tratado na produção de mudas de maracujazeiro azedo. Revista Verde 7: 69-75.

BERNARDI AC de $\mathrm{C}$ et al. 2008. Crescimento e nutrição mineral do porta-enxerto limoeiro 'Cravo' cultivado em substrato com zeólita enriquecida com NPK. Revista Brasileira de Fruticultura 30: 794-800.

BERNARDI ACC et al. 2000a. Desenvolvimento de mudas de citros cultivadas em vaso em resposta à adubação NPK. Scientia Agricola 57: 733-738.

BERNARDI ACC et al. 2000b. Macronutrientes em mudas de citros cultivadas em vasos em resposta à adubação NPK. Scientia Agricola 57: 761-767.

BERNARDI MR et al. 2012. Crescimento de mudas de Corymbia citriodora em função do uso de hidrogel e adubação. Cerne 18: 67-74.

CARNEIRO PAP et al. 2011. Produção de porta-enxerto de limão cravo, em resposta à adubação organomineral. Bioscience Journal 27: 427-432.

CUNHA SOBRINHO AP et al. 2013. Cultivares porta-enxerto. In: Cultura dos citros. Brasília: Embrapa. p.233-292.

FERREIRA DF. 2010. Sisvar: sistema de análise de variância. Versão 5.3. Lavras-MG: UFLA.

FAO. 2018. FOOD AND AGRICULTURE ORGANIZATION. Faostat. Disponível em: http://www.fao.org/faostat/en/\#data/QC. Acesso em: 20 ago. 2018.

FRANZÃO AA et al. 2009. Diferentes métodos de forçamento de brotação na formação de mudas de tangerina cravo. Bioscience Journal 25: 104-111.

FREITAS AS de et al. 2009. Efeito da solarização e materiais orgânicos na incidência de patógenos em mudas de mamoeiro. Revista Verde 4: 108-114.

HARTMANN HT et al. 2010. Plant propagation: principles and practices. 8.ed. New Jersey: Prentice-Hall. 928p.

IBGE. 2018. Instituto Brasileiro de Geografia e Estatística. Sistema IBGE de recuperação automática - Sidra. Disponível em: <https://sidra.ibge.gov.br/home/pnadct/brasil>. Acesso em: 20 ago. 2018. 
INOCÊNCIO MF et al. 2009. Efeito da aplicação de basalto triturado nas características químicas de amostras de solo do estado de Mato Grosso do Sul. Revista Caatinga 22: 145-151.

JABUR MA \& MARTINS ABG. 2002. Influência de substratos na formação dos porta-enxertos: limoeiro-Cravo (Citrus limonia Osbeck) e tangerineira-Cleópatra (Citrus reshni Hort. Ex Tanaka) em ambiente protegido. Revista Brasileira de Fruticultura 24: 514-518.

KOLLER OC (Org.). 2006. Citricultura: 1. laranja: tecnologia de produção, pós-colheita, industrialização e comercialização. Porto Alegre: Cinco Continentes. 396p.

KOLLER OC (Coord.). 2009. Citricultura: cultura de tangerineiras - tecnologia de produção, pós-colheita e industrialização. Porto Alegre: Rígel. 400p.

KIRKBY EA \& RÖMHELD V. 2007. Micronutrientes na fisiologia de plantas: funções, absorção e mobilidade. Encarte Técnico, Norcross: IPNI. 24p.

MACHADO DLM et al. 2011. Slow-release and organic fertilizers on early growth of Rangpur lime. Revista Ceres 58: 359-365.

PRADO RM et al. 2009. Nitrogênio, fósforo e potássio na nutrição e no crescimento de mudas de laranjeira valência, enxertadas sobre limoeiro cravo. Ciência e Agrotecnologia 33: 1560-1568.

RAMOS RA et al. 2010. Variação sazonal do crescimento vegetativo de laranjeiras Hamlin enxertadas em citrumeleiro Swingle no município de Limeira, Estado de São Paulo. Acta Scientiarum. Agronomy 32: 539-545.

RAVEN PH et al. 2001. Biologia Vegetal. Rio de Janeiro: Guanabara-Koogan. 6.ed. 906p.

ROZANE DE et al. 2009. Efeito das doses de nitrogênio, fósforo e potássio na nutrição e na produção do porta-enxerto de limoeiro cravo. Acta Scientiarum. Agronomy 31: 255-260.

SÁ JR de et al. 2010. Interação da adubação organo-mineral nos atributos químicos do solo na cultura do melão em Mossoró - RN - Brazil. Revista Verde 5: 89-100.

SCIVITTARO WB et al. 2004. Adubação nitrogenada na formação de porta-enxertos de limoeiro 'Cravo' em tubetes. Revista Brasileira de Fruticultura 26: 131-135.

SCHÄFER G et al. 2006. Desenvolvimento vegetativo inicial de porta-enxertos cítricos cultivados em diferentes substratos. Ciência Rural 36: 1723-1729.

SILVA EA da et al. 2010. Composição de substratos e tamanho de recipientes na produção e qualidade das mudas de maracujazeiro 'amarelo'. Ciência e Agrotecnologia 34: 588-595.

TAIZ L \& ZEIGER E. 2009. Fisiologia vegetal. 4.ed. Trad. Porto Alegre: Artmed Editora. 819p.

TEIXEIRA PTL et al. 2009. Desenvolvimento vegetativo de porta-enxertos de citros produzidos em diferentes recipientes. Ciência Rural 39: 1695-1700.

TOFANELLI MBD et al. 2016. Aplicação em cobertura de complexo hidrossolúvel na formação de mudas de maracujazeiro-azedo. Científica 44: 196-206.

TOFANELLI MBD \& SILVA TO. 2011. Manejo ecológico e conservação dos solos e da água no estado de Sergipe. 1.ed. São Cristóvão: Editora UFS. 358p.

VALE DW \& PRADO RM. 2009. Adubação com N, P e K no crescimento inicial do porta-enxerto limoeiro cravo. Revista Brasileira de Ciências Agrárias 4: 35-41.

VALE DW et al. 2009. Doses de nitrogênio, fósforo e potássio na nutrição do porta-enxerto cítrico de limoeiro 'cravo'. Scientia Agraria 10: 61-66.

WEILER RL et al. 2009. Teste de paternidade e avaliações agronômicas de possíveis híbridos de tangerineira 'Sunki'. Scientia Agraria 10: 429-435. 